\title{
Lipid Chemistry
}

National Cancer Institute

\section{Source}

National Cancer Institute. Lipid Chemistry. NCI Thesaurus. Code C18862.

The 'test tube' chemical reactions of lipids-not involving enzymes 